\title{
Experimental study of the form of "hot" steel particles on the ignition characteristics of liquid fuels
}

\author{
Arkadiy V. Zakharevich ${ }^{\mathrm{a}}$ \\ National Research Tomsk Polytechnic University, 634050 Tomsk, Russia
}

\begin{abstract}
The results of an experimental study of laws governing the ignition of liquid propellants (kerosene, diesel fuel and petroleum residue) by the single spherical steel particle heated to high temperatures are presented. Is carried out the comparison of the ignition delay times of the investigated flammable substances by the particles in the sphere and disk forms. It is established that the particle shape does not exert a substantial influence on the ignition process characteristics.
\end{abstract}

\section{Introduction}

As a result of experimental studies [1-3] found that the high temperature of the particle in the form of a disk are sustainable sources of ignition typical liquid fuels (kerosene, diesel fuel, fuel oil) at temperatures above $1230 \mathrm{~K}$. Worked out the mathematical models and theoretical research of the conditions and characteristics of the ignition of liquid fuels in heating local sources of energy in the form of a disk $[4,5]$. Quite often, in practice, the heated particles are spherical, so it is reasonable to study the ignition of liquid fuel particles in the form of a sphere. This will determine the degree of influence of particle shape on the parameters of the ignition.

The purpose of work - experimental study of fire ignition fuels single heated to a high temperature steel particle in the form of a sphere and the data obtained are compared with the results of similar studies for particles in the form of a disk.

\section{Experimental research methodology}

Research used the experimental setup [6], whose main elements are heating furnace and the controlmeasuring installation. When planning the experiment was chosen as the most typical pattern: the metal particle falls perpendicular to the surface of the liquid at a low speed - no more than $1.7 \mathrm{~m} / \mathrm{s}$. On the basis of such a scheme is fixed to the height of the fall of the particle, which does not happen spontaneous combustion of fuel from the heating furnace. Particle immersed in the fluid not completely. Experiments were carried out for the particle in the form of spheres (diameter $d_{\mathrm{p}}=6 \cdot 10^{-3} \mathrm{~m}$ ) and diskshaped $\left(d_{\mathrm{p}}=6 \cdot 10^{-3} \mathrm{~m}, h_{\mathrm{p}}=3 \cdot 10^{-3} \mathrm{~m}\right)$. Was used glass vertical vessel sizes height $h=4 \cdot 10^{-2} \mathrm{~m}$

\footnotetext{
${ }^{\text {a }}$ Corresponding author: bet@tpu.ru
}

This is an Open Access article distributed under the terms of the Creative Commons Attribution License 4.0, which permits unrestricted use, distribution, and reproduction in any medium, provided the original work is properly cited. 


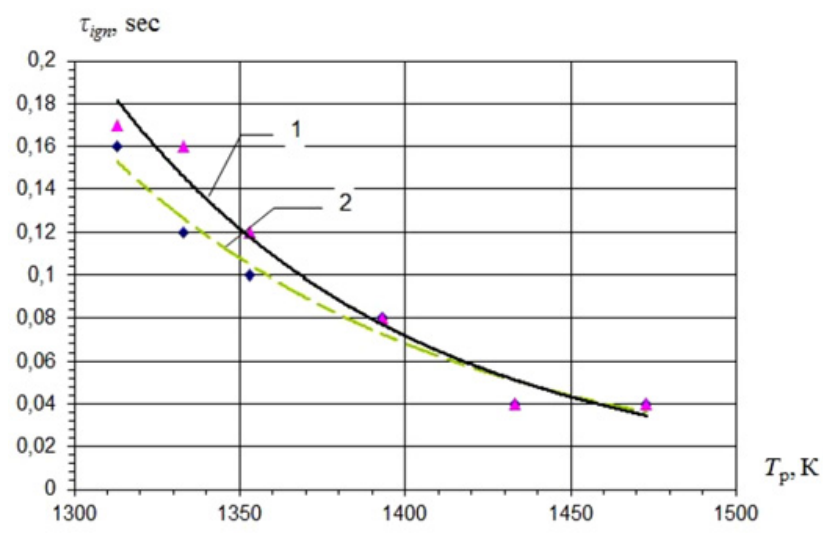

Figure 1. Experimental dependence of the ignition delay of diesel fuel from the particle temperature: 1 - hot particle-sphere $d_{\mathrm{p}}=6 \cdot 10^{-3} \mathrm{~m}, 2$ - hot particle-disk $d_{\mathrm{p}}=6 \cdot 10^{-3} \mathrm{~m}, h_{\mathrm{p}}=3 \cdot 10^{-3} \mathrm{~m}$.

и $d=5 \cdot 10^{-2} \mathrm{~m}$. Temperature particulate matter $\left(T_{\mathrm{p}}\right)$ is significantly higher than the initial temperature of the liquid fuel $(300 \mathrm{~K})$. To ensure the reliability of measurement results carried out a series experiments (4-6 times in a row in the same conditions). In all the experiments carried out video of the processes studied. Ignition delay $\tau_{\text {ign }}$ determined from the time of contact with the surface of the particles of the fire hazardous substances to the appearance of the flame.

\section{Results of experimental studies}

The experiments were conducted with spherical metal particles with a diameter equal to the diameter of the particles was discs previously studied [1]. Figures 1-3 shows the experimental depending the ignition delay time $\tau_{\text {ign }}$ of particle temperature $T_{\mathrm{p}}$ when ignited kerosene, diesel and fuel oil with steel particles in the shape of a sphere and disk. The curves are plotted as a result of approximation the experimental data. Approximation curves were obtained by least squares. The variation coefficient of the experimental data at constant temperature did not exceed $10 \%$. The experiments were performed for particles with equal area of Middel section. As seen from the results of experiments the ignition delay time difference in disk-shaped particles and spheres of the investigated liquid fuel is no more than $18 \%$. Such a deviation of the experimental data is observed at the initial (minimum) temperature ignition of liquid fuel. With further increase in temperature of the particles scattering of experimental data is reduced.

Based on the experimental results it can be concluded that the shape of the particles has little effect on the character of the ignition of the liquid fuel. Established regularities can be explained as follows. Experiments for the three abovementioned liquid fuels conducted under identical conditions. The particle were immersed in liquid on average no over than $1.5 \mathrm{~mm}$. At the identical dive disc and spheres contact area $\left(S_{\mathrm{k}}\right)$ particles of different shapes differed. The value $S_{\mathrm{k}}$ was 1.5 times less than for the particle-sphere. Therefore, the amount of heat transmitted into the liquid in the experiments with particles in the form of spheres was lower than in the experiments with particles in the form of a disk. The difference of the time delay ignition, apparently due to the fact that the particle disc after immersion in diesel fuel heats it mainly due to heat dissipation from the side surface. The end surface of the diskshaped particle weakly involved in the transmission energy in the fuel, after the disc-shaped has reached the bottom of the vessel with liquid. The particle shape of a sphere in contact with the bottom of the vessel at only one point and the rest of the surface is cooled due to heat transfer to the fuel, in contrast 


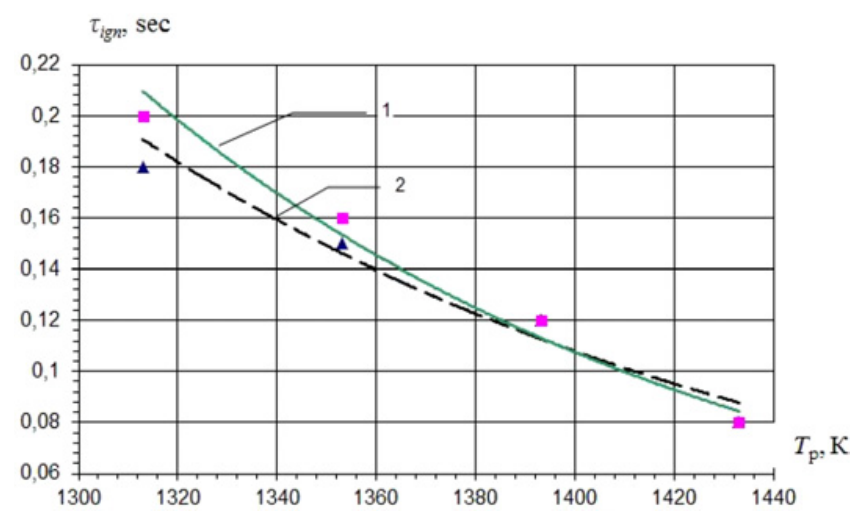

Figure 2. Experimental dependence of the ignition delay time of kerosene from the particle temperature: $1-$ hot particle-sphere $d_{\mathrm{p}}=6 \cdot 10^{-3} \mathrm{~m}, 2$ - hot particle-disk $d_{\mathrm{p}}=6 \cdot 10^{-3} \mathrm{~m}, h_{p}=3 \cdot 10^{-3} \mathrm{~m}$.

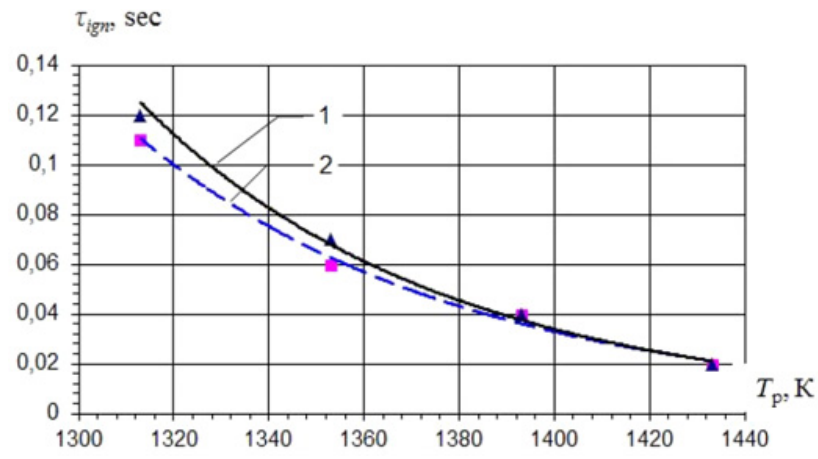

Figure 3. Experimental dependence of the ignition delay of fuel oil from the particle temperature: 1 - hot particlesphere $d_{\mathrm{p}}=6 \cdot 10^{-3} \mathrm{~m}, 2-$ hot particle-disk $d_{\mathrm{p}}=6 \cdot 10^{-3} \mathrm{~m}, h_{\mathrm{p}}=3 \cdot 10^{-3} \mathrm{~m}$.

to the disk. Formally, the area of contact with the fluid particles-disk lying at the bottom was 1.5 times smaller than the particles-spheres under similar conditions.

However it is necessary be noted that the particle-disk sank to the bottom of the vessel and passed through the fuel at a finite rate, heating the liquid by cooling the bottom wall surface during the time slot corresponding to its motion. In this case, are formed pair of fuel moving with high speed up impeded motion of the particle-disk and significantly reduced the rate of its downward movement. As a result, the heat accumulated in the particle-disk, quite intensively (not less intense than for the particle-sphere) was transferred to the fuel.

And even after the particle-disk reaches the bottom of the vessel, due to the surface roughness of the glass vessel and the particle-disk between them was not perfect contact. Located between their surfaces in the roughness elements (such as cracks, gouges, gaps) of the fuel evaporates intensively, and formed in this vaporous products locally getting out of hand disc with high churn.

For these reasons, eventually the difference values $\tau_{\text {ign }}$ particles in the form of a sphere and the disc does not exceed $18 \%$ in the case of relatively low initial temperature of the heat source and tends to zero when increase of the temperature.

A comparison of the numerical values $\tau_{\text {ign }}$, obtained under identical conditions for diesel, kerosene and fuel oil (to look Figs. 1, 2 and 3, respectively), allows to make another important conclusion. Over the entire range temperatures, the lowest value of the ignition delay time is fixed when the ignition of 
fuel oil. This unobvious at first glance, the result is due to the peculiarities processes of formation a vapor investigated liquid fuels. Fuel oil belongs to fuels with high of coke residue pyrolysis process (cracking) of the starting material. Therefore, the transition from the liquid into a state the characteristic for ignition of the fuel is necessary in other appropriate conditions the smallest amount of energy out of three the liquids. At evaporation (gasification) of kerosene is formed the minimum compared with diesel fuel and fuel oil quantity solid products and, accordingly, the heat of evaporation of the maximum. Ignition process for the preparation of a unit mass kerosene is necessary to spend the most compared to with fuel oil and diesel fuel amount of heat. Therefore, the ignition delay time of kerosene in the same fuel oil and diesel fuel conditions should be the greatest.

\section{Conclusions}

Investigated experimentally the ignition group of typical liquid fuels single heated to a high temperature metal particles in the shape of a sphere (particles-sphere) and a disk (particles-disk). Based on the obtained the result of the experimental studies of the dependences $\tau_{\text {ign }}$ and $T_{\mathrm{p}}$, we can conclude about the possibility of using the results obtained earlier for the particles in the form of a disc in the analysis of the ignition delay time of liquid fuel particles in the form of a sphere when the identical characteristic size. The deviation $\tau_{\text {ign }}$ from the true value at the same time will not exceed the error of experimental methods for determining the ignition delay time under the conditions considered.

\section{References}

[1] A.V. Zakharevich, G.V. Kuznetsov, V.I. Maksimov, Panin V.F., and Ravdin D.S., Izvestia Tomskogo politehnicheskogo universiteta. 313, 25 (2008)

[2] P.A. Strizhak, A.V. Zakharevich, Journal of Engineering Thermophysics. 22, 157 (2013)

[3] A.V. Zakharevich, G.V. Kuznetsov, Belkov N.S., Chemicheskoe and neftegazovoe mashinostroenie. 7, 9 (2014)

[4] P.A. Strizhak, Journal of Engineering Thermophysics. 20, 211 (2011)

[5] P.A. Strizhak, Journal of Engineering Thermophysics. 4, 459 (2011)

[6] A.V. Zakharevich, G.V. Kuznetsov, V.I. Maksimov, and V.T. Kuznetsov, Combustion, Explosion, and Shock Waves. 5, 543 (2008)

[7] A.V. Zakharevich, V.T. Kuznetsov, G.V. Kuznetsov, V.I. Maksimov, Combust. Explos., Shock Waves. 44, 543 (2008) 